\title{
Subcycling-PCR for Multiplex Long-Distance Amplification of Regions with High and Low GC Content: Application to the Inversion Hotspot in the Factor VIII Gene
}

BioTechniques 25:1022-1028 (December 1998)

\author{
Qiang Liu and Steve S. \\ Sommer \\ City of Hope National Medical \\ Center, Duarte, CA, USA
}

\section{ABSTRACT}

Previously we described a PCR protocol for detecting the inversion in the factor VIII gene, which is a common cause of Hemophilia A. This PCR assay is challenging due to the size of the amplification (10-12 kb), the varying $G C$ content $(30 \%-80 \%)$ and the multiplex PCR products involved (four for carrier female). Efficient amplification of the four segments depends on three unusual modifications to standard long-distance PCR protocols: (i) very high concentrations of dimethyl sulfoxide, (ii) addition of deaza$d G T P$ and (iii) high concentration of Taq and Pwo DNA polymerases. One of the segments was amplified much more efficiently than the others under standard three-temperature cycling conditions $\left(12\right.$ s at $94^{\circ} \mathrm{C}$, $30 \mathrm{~s}$ at $65^{\circ} \mathrm{C}$ and $14 \mathrm{~min}$ at $68^{\circ} \mathrm{C}$ ). To facilitate the uniform amplification of the multiple regions, subcycling-PCR (S-PCR) was developed. In S-PCR, the combined annealing/elongation step is composed of subcycles of shuttling between a low and a high temperature, e.g., shuttling four times between $60^{\circ}$ and $65^{\circ} \mathrm{C}$. $S$-PCR produces consistent robust amplification of the various segments produced by wild-type, mutant and carrier individuals. S-PCR is a simple generalization of $P C R$, which generally may be advantageous in three contexts: (i) amplification of long segments in which the GC content varies within the segment, (ii) multiplex amplification of long segments and (iii) multiplex amplification of short segments in which the GC content varies among the segments.

\section{INTRODUCTION}

Hemophilia A is one of the most common coagulation disorders, with an incidence of about one in 5000 males. The disease is caused by mutations in the factor VIII gene. Inversions within the factor VIII gene cause almost half of all cases of severe hemophilia A. A 9.5$\mathrm{kb}$ region of intron 22 (Int 22hl) is repeated twice near the $\mathrm{Xq}$ telomere (Int22h2 and Int22h3). These repeated sequences are more than $99 \%$ identical with one another (12). The inversion occurs by intra-chromosomal homologous recombination between Int $22 \mathrm{hl}$ and an extragenic homolog (either Int $22 h 2$ or Int $22 h 3$, known as Types I and II inversions, respectively) $(1,7,11)$. The inversions are detected routinely by timeconsuming, costly Southern blots using a probe from Int $22 \mathrm{hl}$. Successful polymerase chain reaction (PCR) amplification spanning these regions has not been reported, presumably because the regions contain a $3.5-\mathrm{kb}$ GC island of $65 \% \mathrm{GC}$ content and a $1-\mathrm{kb}$ region of $79 \%$ GC content within the GC island (Figure 1).

A single-tube PCR assay was reported that combines overlapping PCR (9) with long-distance PCR $(2,5)$ to differentiate the wild-type, affected males and female carriers (Figure 2). Herein, we supplement the initial clinical report
(8) by analyzing parameters affecting amplification.

Multiplex PCR is a rapid and convenient method, but uneven amplification is common (4). Efforts have been made to achieve uniform amplification. Since primer concentration is often difficult to optimize, a simplified optimization procedure was developed based on the use of chimeric primers (14). Each primer contains a $3^{\prime}$ region complementary to sequence-specific recognition sites and a $5^{\prime}$ region made up of a universal 20-nucleotide (nt) sequence. Each individual PCR was first optimized by adjusting primer concentrations, cycling times and annealing temperatures. In another approach, two detergents, dimethyl sulfoxide (DMSO) and betaine, were combined to achieve uniform amplification for three templates differing in GC contents (3). Additional approaches include adjusting the annealing temperature, $\mathrm{KCl}$ (salt) concentration and primer concentration for each locus encountered in developing multiplex PCR of small sizes (6). Herein, we describe subcycling-PCR (S-PCR), a novel method for this purpose.

\section{MATERIALS AND METHODS}

\section{Primer Design of the PCR Assay}

A major difficulty in developing the PCR assay was lack of sufficient flanking sequences to design the PCR primers. Fifty base pair of 5' flanking sequence of Int $22 \mathrm{hl}$ in intron 22 were 
Table 1. Oligonucleotide Positions and Sequences

\begin{tabular}{|lrc|}
\hline Name/Position & Sequence No. & $\begin{array}{c}\text { GenBank } \\
\text { Accession No. }\end{array}$ \\
\hline $\mathrm{P}(-1212)$ & gcc cTG CCT GTC CAT TAC ACT GAT GAC ATT ATG CTG AC & AF062514 \\
$\mathrm{Q}(+1334)$ & ggc ccT ACA ACC ATT CTG CCT TTC ACT TTC AGT GCA ATA & X86012 \\
A $(-167)$ & CAC AAG GGG GAA GAG TGT GAG GGT GTG GGA TAA GAA & AF062515 \\
B $(+118)$ & ccC CAA ACT ATA ACC AGC ACC TTG AAC TTC CCC TCT CATA & AF062516 \\
Note: The high GC tails are indicated as lower case letters. The primer's first base at 5' end of the sequence-specific region is \\
assigned, - = before the homolog and + = after the homolog.
\end{tabular}

Table 2. The Key Parameters

\begin{tabular}{|c|c|c|}
\hline \multicolumn{2}{|c|}{ Component Changeda } & \multirow{2}{*}{ Amplifications } \\
\hline DSMO (\%) & 10.5 & \\
\hline & 9 & ++ \\
\hline & 7.5 & +++ \\
\hline & 6 & ++ \\
\hline & 4.5 & - \\
\hline & 0 & - \\
\hline \multirow[t]{4}{*}{$\begin{array}{c}\text { deaza-dGTP:dGTP } \\
(\%: \%)\end{array}$} & $50: 50$ & $\begin{array}{l}+++/++ \\
(\mathrm{AB} / \mathrm{PQ})^{\mathrm{b}}\end{array}$ \\
\hline & $37.5: 62.5$ & $+++/+++$ \\
\hline & $25: 75$ & $++/++$ \\
\hline & $0: 100$ & $-/-$ \\
\hline \multirow[t]{7}{*}{$\begin{array}{l}\text { Taq/Pwo } \\
(\mathrm{U} / 25 \mu \mathrm{L})\end{array}$} & 10 & $\begin{array}{l}+++/+++ \\
(\mathrm{AB} / \mathrm{PQ})\end{array}$ \\
\hline & 5 & $+++/+++$ \\
\hline & 2.5 & $+++/++$ \\
\hline & 1.25 & $+++/+$ \\
\hline & 0.625 & $++/-$ \\
\hline & 0.3125 & $-/-$ \\
\hline & 0 & $-/-$ \\
\hline \multicolumn{3}{|c|}{$\begin{array}{l}\text { aOnly one component was changed. The effect was tested with the four primers } \\
\text { (each at } 0.2 \mu \mathrm{M}) \text { at } 65^{\circ} \mathrm{C} \text { for the annealing/elongation. } \\
\text { bAB and } \mathrm{PQ} \text { segments are indicated in order. }\end{array}$} \\
\hline
\end{tabular}

available from GenBank ${ }^{\circledR}$ (Accession No. X86011). A 6-kb PCR was amplified spanning the exon 22 and $5^{\prime}$ end of Int $22 \mathrm{hl}$ with the Expand ${ }^{\mathrm{TM}}$ Long Template PCR System (Boehringer Mannheim, Indianapolis, IN, USA). An additional 1319 bp of the 5' flanking sequence were obtained by automatic sequencing (GenBank Accession No.
AF062514). Only $50 \mathrm{bp}$ of both $5^{\prime}$ and $3^{\prime}$ flanking sequences were known for Int $22 h 2$ and Int $22 h 3$ (12). A 6-kb region including Int $22 h 2$ flanking sequences was amplified by inverse-PCR (13). Additional 5' and 3' flanking sequences of Int $22 \mathrm{~h} 2$ (695 and $412 \mathrm{bp}$, respectively) were obtained (GenBank Accession Nos. AF062515 and AF06-
2516) and were confirmed to be identical in Int $22 h 3$ by PCR amplification of patients with Type I and Type II inversions, as previously determined by Southern blot analysis.

The primers $\mathrm{P}, \mathrm{Q}, \mathrm{A}$ and $\mathrm{B}$ were designed with the aid of OLIGO ${ }^{\mathrm{TM}}$ Version 5 software (National Biosciences, Plymouth, MN, USA). The melting temperature $\left(\mathrm{T}_{\mathrm{m}}\right)$ value of each PCR segment was estimated by the formula of Wetmur: $\mathrm{T}_{\mathrm{m}}$ product $=81.5+16.6 \mathrm{log}$ $\left[\mathrm{K}^{+}\right]+0.41 \%$ (GC) -675/length (16). The GC content of the AB segment is $51 \%$ on average, and the $\mathrm{T}_{\mathrm{m}}$ is $81^{\circ} \mathrm{C}$. The $\mathrm{T}_{\mathrm{m}}$ values of the primers were estimated by the nearest-neighbor method at $50 \mathrm{mM} \mathrm{KCl}$ and $250 \mathrm{pM}$ DNA with the formula: $\mathrm{T}_{\mathrm{m}}$ primer $=\Delta \mathrm{H} /\{\Delta \mathrm{S}+\mathrm{R} \times$ $\ln (\mathrm{C} / 4)\}+16.6 \log \left[\mathrm{K}^{+}\right]-273.15$. Each primer was designed to have a $\mathrm{T}_{\mathrm{m}}$ that was $10^{\circ} \mathrm{C}$ lower than the average $\mathrm{T}_{\mathrm{m}}$ of the PCR products $\left(73^{\circ} \mathrm{C}\right)$. Primer lengths varied from 36-40 nt. For primers $\mathrm{P}, \mathrm{Q}$ and $\mathrm{B}$, a high $\mathrm{GC}$ tail of 2-5 nt was added to achieve a $\mathrm{T}_{\mathrm{m}}$ value of $73^{\circ} \mathrm{C}$. Formation of primer dimers was minimized by designing the $3^{\prime}$ end of each primer to have no more than 4 nt of intra-strand and inter-strand complementarity. Finally, there were no more than six bases of complementarity at the $3^{\prime}$ end of any primer to any of the PCR products. The positions and sequences of the oligonucleotides are described in Table 1.

\section{The PCR Assay}

The PCR was performed from human genomic DNA isolated from white blood cells. Unless stated, the PCR mixtures contained a total volume of 25 $\mu \mathrm{L}: 50 \mathrm{mM}$ Tris-HCl, pH 9.2, $2.25 \mathrm{mM}$ 


\section{Research Reports}

Table 3. Comparison of Different Enzyme Systems

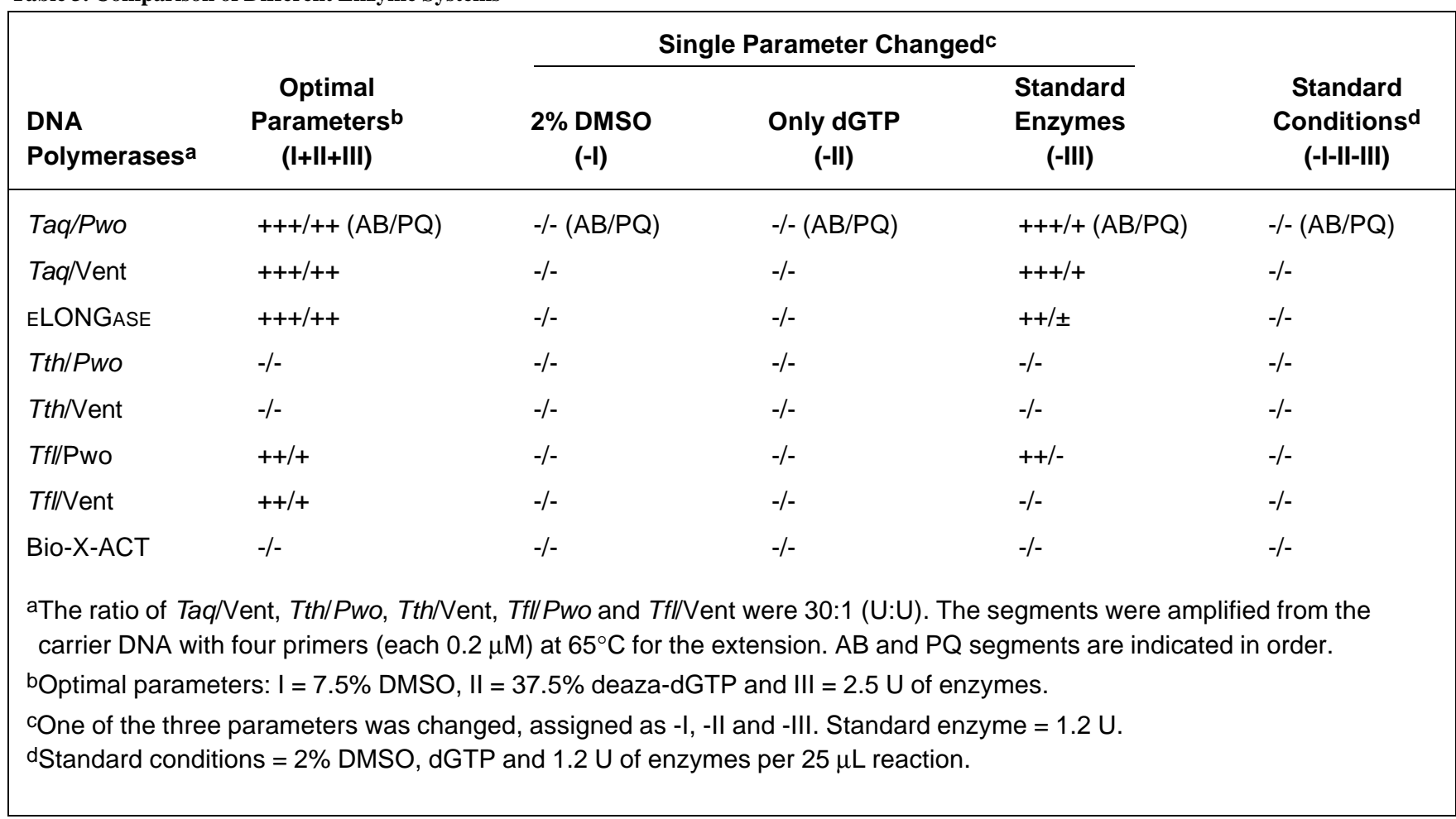

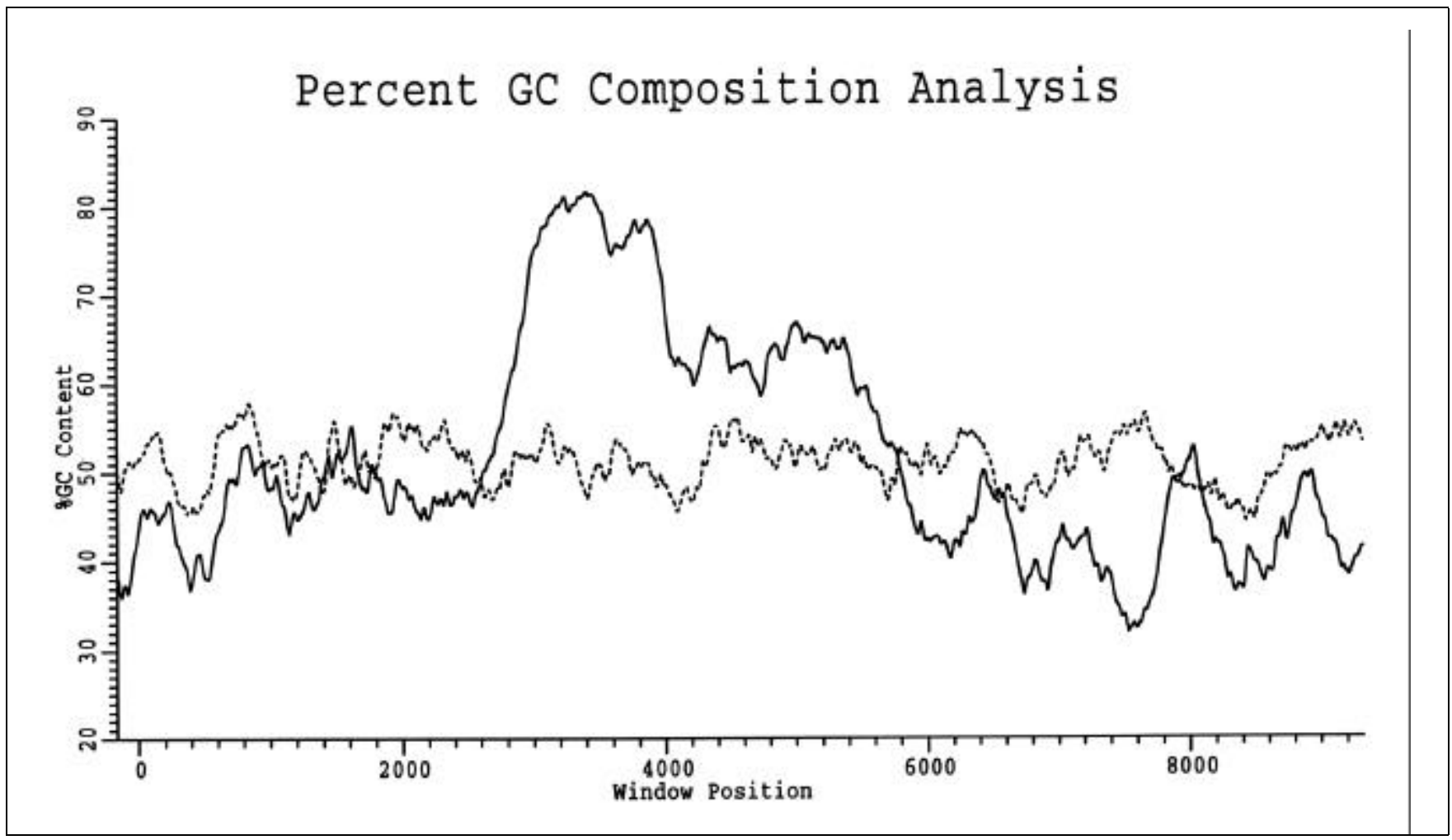

Figure 1. Map plot of GC content of segment AB. The Y-axis indicates the GC content of the sequential windows of $300 \mathrm{nt}$. The solid line plots the GC content of segment $\mathrm{AB}$, and the dotted line plots the GC content of segment AB after random shuffling. Composition analysis of symbol number range -166-9623 using a sliding analysis window of 300 symbols and smoothed by a 21 -symbol moving average filter. The solid line denotes the AB segment, and the broken line denotes the AB segment shuffled. 
$\mathrm{MgCl}_{2}, 16 \mathrm{mM}\left(\mathrm{NH}_{4}\right)_{2} \mathrm{SO}_{4}, 7.5 \%$ DMSO, $500 \mu \mathrm{M}$ of dGTP and deazadGTP $(62.5 \%: 37.5 \%$ or $50 \%: 50 \%)$, $500 \mu \mathrm{M}$ of each of the other dNTPs and $250 \mathrm{ng}$ of genomic DNA. Three types of cycling conditions were utilized: three-temperature-, two-temperatureand S-PCR. The cycling conditions for three-temperature PCR were $94^{\circ} \mathrm{C}$ for $12 \mathrm{~s}, 65^{\circ} \mathrm{C}$ for $30 \mathrm{~s}$ and $68^{\circ} \mathrm{C}$ for $14 \mathrm{~min}$ for the first 10 cycles $\left(\right.$ GeneAmp ${ }^{\circledR}$ PCR System 9600; PE Applied Biosystems, Foster City, CA, USA). The remaining 20 cycles were performed by adding an extra $20 \mathrm{~s}$ to the elongation per cycle.
Conditions for two-temperature PCR were: $94^{\circ} \mathrm{C}$ for $12 \mathrm{~s}$ and $65^{\circ} \mathrm{C}$ for 15 $\min$ for the first 10 cycles, with an extra $20 \mathrm{~s}$ added to the elongation per cycle for the remaining 20 cycles. The conditions for S-PCR for the first 10 cycles were: $94^{\circ} \mathrm{C}$ for $12 \mathrm{~s}$, followed by four subcycles of annealing/elongation that involve $60^{\circ} \mathrm{C}$ for $120 \mathrm{~s}$ and $65^{\circ} \mathrm{C}$ for $120 \mathrm{~s}$ for each subcycle. The remaining 20 cycles were modified by the addition of an extra $3 \mathrm{~s}$ per cycle for each step of the annealing/elongation step. An additional 2 min of denaturation was utilized in the first cycle. The en-

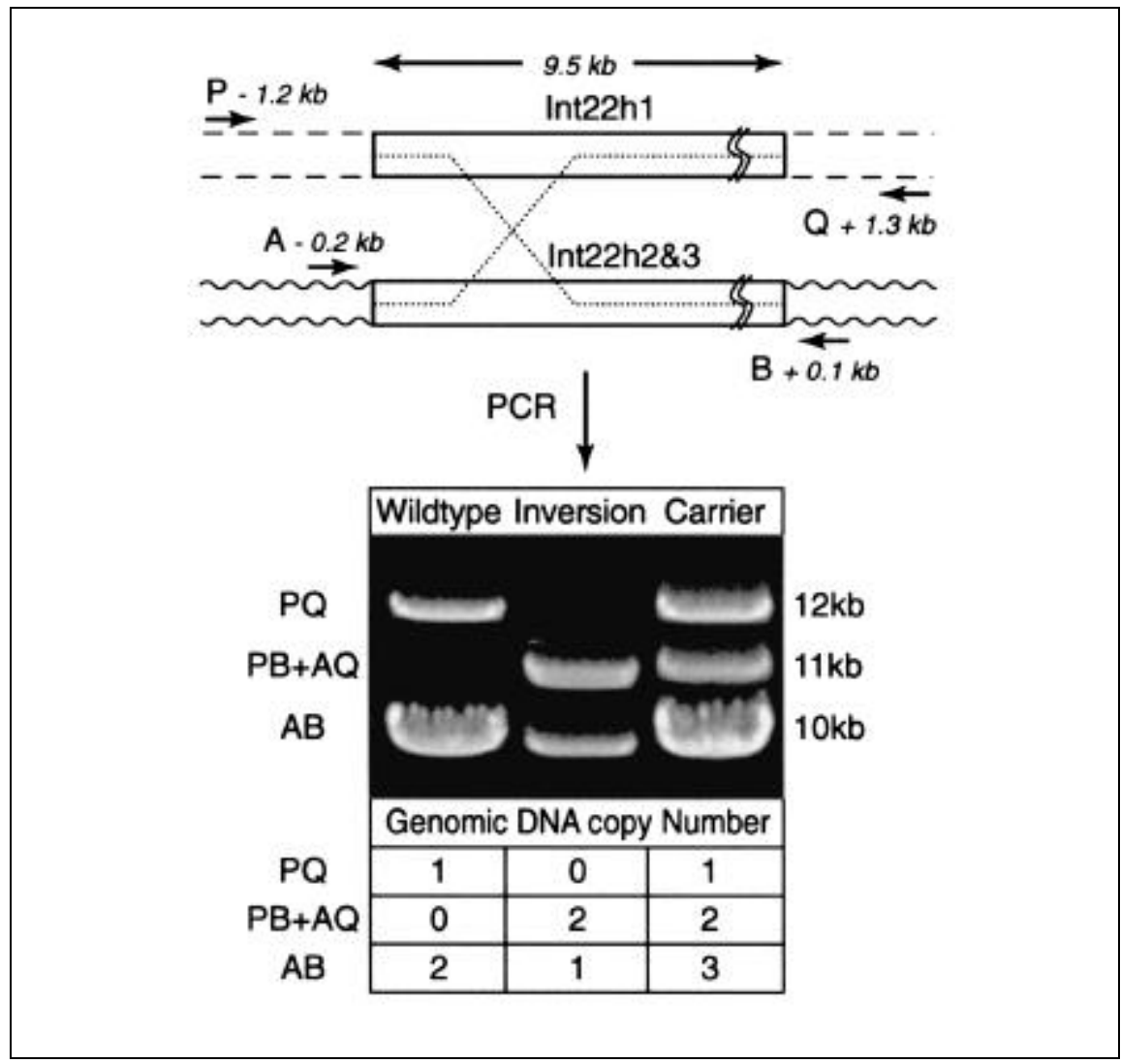

Figure 2. Schematic of the PCR assay. At the top, the locations of four primers (P, Q, A and B) are represented by arrows. The upper box represents Int $22 \mathrm{hl}$, and the dashed lines indicate the flanking sequences. The lower box represents Int $22 h 2$ and Int $22 h 3$, and the wavy lines indicate the flanking sequences. Deleterious inversions can occur by recombination between Int $22 h 1$ and either Int $22 h 2$ or Int22h3 (dotted lines). The PCR amplifies overlapping and multiplex segments from genomic DNA with four primers $\mathrm{P}, \mathrm{Q}, \mathrm{A}$ and $\mathrm{B}$ to generate four potential segments $\mathrm{PQ}, \mathrm{AB}, \mathrm{PB}$ and $\mathrm{AQ}$. Two primers, $\mathrm{P}$ and $\mathrm{Q}$, are specific to the flanking sequences of Int 22hl, located at $-1212 \mathrm{bp}$ before and at $+1334 \mathrm{bp}$ after the homolog; two primers, A and B, are specific to the flanking sequences of Int $22 \mathrm{~h} 2$ and Int $22 \mathrm{~h} 3$, located at $-167 \mathrm{bp}$ before and at $+118 \mathrm{bp}$ after the homologs. $\mathrm{P}$ and $\mathrm{Q}$ anneal at different distances from $\mathrm{A}$ and $\mathrm{B}$ to differentiate PQ (12 kb), AB (10 kb) and PB+AQ (11 kb each) segments on agarose gels. Genomic DNA from wild-type, male patient or female carrier samples produces three patterns of amplification. PQ is produced in a wild-type sample, $\mathrm{PB}+\mathrm{AQ}$ is generated in males with the inversion and both $\mathrm{PQ}$ and $\mathrm{PB}+\mathrm{AQ}$ are present in the carriers. $\mathrm{AB}$ is always produced and serves as a positive control, because at least one copy of Int $22 \mathrm{~h} 2$ and Int $22 \mathrm{~h} 3$ remains intact. S-PCR was performed with each primer at $0.2 \mu \mathrm{M}$. The relative copy numbers of segments $\mathrm{PQ}, \mathrm{AB}$ and $\mathrm{PB}+\mathrm{AQ}$ before amplification are indicated at the bottom, although some individuals have one or more extra copies of Int $22 h 2$ or Int $22 h 3$ located on the X chromosome or autosome.

zyme amount and primer concentration depended on the types of cycling conditions for Expand Long Template DNA Polymerase (Boehringer Mannheim), amounts of enzyme and primers $(\mathrm{P}, \mathrm{Q}$, $\mathrm{A}$ and $\mathrm{B}$ ) are as follows: (i) for threetemperature PCR, $3.3 \mathrm{U}$ and $0.4,0.4$, 0.12 and $0.12 \mu \mathrm{M}$, (ii) for two-temperature PCR, $2.5 \mathrm{U}$ and $0.2,0.2,0.15$ and $0.15 \mu \mathrm{M}$ and (iii) for S-PCR, $2.5 \mathrm{U}$ and $0.2,0.2,0.2$ and $0.2 \mu \mathrm{M}$. Ten microliters of the reaction were mixed with an equal amount of $2 \times$ loading buffer (5\% Ficoll ${ }^{\circledR} 400,5 \mathrm{mM} \mathrm{MgCl}_{2}, 25 \mathrm{mM}$ $\mathrm{NaCl}, 10 \mathrm{mM}$ Tris-HCl, pH 7.9) and then incubated at $37^{\circ} \mathrm{C}$ for $5 \mathrm{~min}$. Samples were electrophoresed on a $0.6 \%$ agarose gel and then stained with ethidium bromide for UV photography by a charge-coupled device (CCD) camera (Gel Doc ${ }^{\mathrm{TM}}$ 1000; Bio-Rad, Hercules, CA, USA).

\section{RESULTS}

\section{Utility of DMSO, deaza-dGTP and High Concentrations of DNA Polymerase}

A PCR-based assay for the inversion was developed to distinguish among the wild-type, inversion and carrier states. Herein, we report an analysis of

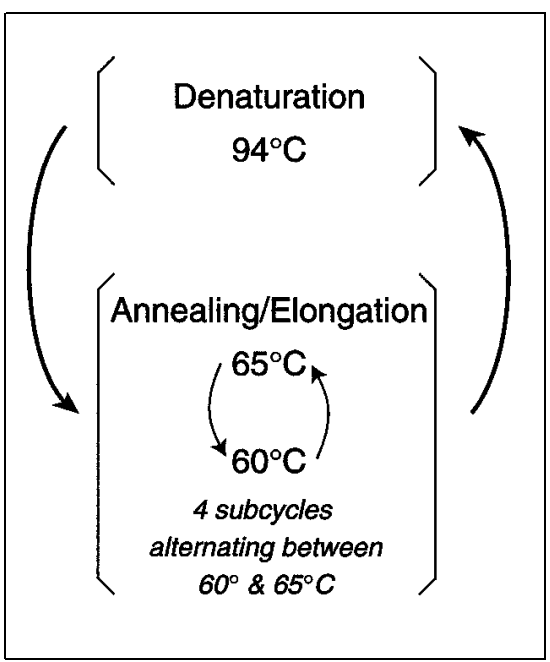

Figure 3. Schematic of subcycling-PCR. Each cycle of S-PCR involves a denaturation step and an annealing/elongation step. The annealing/ elongation step is composed of subcycles to shuttle among low and high temperatures. $\mathrm{m}=$ the number of shuttled temperatures within a subcycle $\geq 2, \mathrm{n}=$ the number of subcycles $\geq 1, \mathrm{~m} \times \mathrm{n}>3$. 


\section{Research Reports}

the PCR parameters important for the amplification (Figure 4 and Table 2). Successful amplification required 6\%9\% DMSO, 25\%-50\% deaza-dGTP, and 1.25-10 U enzymes, with optimal results achieved at $5-10 \mathrm{U}$ per $25 \mu \mathrm{L}$ reaction.

Analysis of several other DNA polymerase combinations [Taq and Vent ${ }^{\circledR}$ (Boehringer Mannheim and New England Biolabs, Beverly, MA, USA, respectively), ELONGASE ${ }^{\mathrm{TM}}$ Enzyme mixture, which contains Taq and $G B-D$ (Life Technologies, Gaithersburg, MD, USA), Tth and $P$ wo (Boehringer Mannheim), Tth and Vent, Tfl (Promega, Madison, WI, USA) and Pwo, Tfl and Vent and Bio-X-ACT ${ }^{\mathrm{TM}}$ DNA Polymerase (Intermountain Scientific, Kaysville, UT, USA)] indicated that high concentrations of DMSO and deazadGTP were critical for all enzymes studied, while high enzyme concentration was helpful but not universally critical (Figure 4 and Table 3 ).

\section{Subcycling-PCR Achieves Even and Efficient Amplification}

Despite substantial efforts at optimization, segment $A B$ was amplified much more efficiently than segments PQ, PB or AQ with standard three-temperature PCR (Figure 4A, lane 1). Preferential amplification is often a problem in multiplex PCR, especially if segments with divergent GC contents are amplified. Although even one nucleotide change in a sequence sometimes causes differential amplification (10), we reasoned that areas of low GC content in the $2.5 \mathrm{~kb}$ of the flanking sequences present in segment PQ could account for some or all of the differential efficiency of amplification. Since the optimal extension temperature varies with GC content (15), the annealing/elongation temperature was lowered. Much of the differential amplification was eliminated, but the yields of amplified product were both lowered and inconsistent with a faint spurious segment (Figure 5, lanes 1-6). To obtain high and relatively uniform yields, we developed S-PCR, which is characterized by "subcycling parameters" within the annealing/elongation step (Figure 3). With the subcycling parameters between $60^{\circ}$ and $65^{\circ} \mathrm{C}, \mathrm{S}$ -
PCR amplified the four segments more evenly and efficiently with the four primers from the carrier DNA template (Figure 5, lane 7). When the wild-type and inversion templates were used, the same results were obtained. Similar results were obtained with a four-step subcycling program: two subcycles at $60^{\circ}, 64^{\circ}, 68^{\circ}$ and $64^{\circ} \mathrm{C}$ for $2 \mathrm{~min}$ each, for a total of $16 \mathrm{~min}$ (data not shown).

A

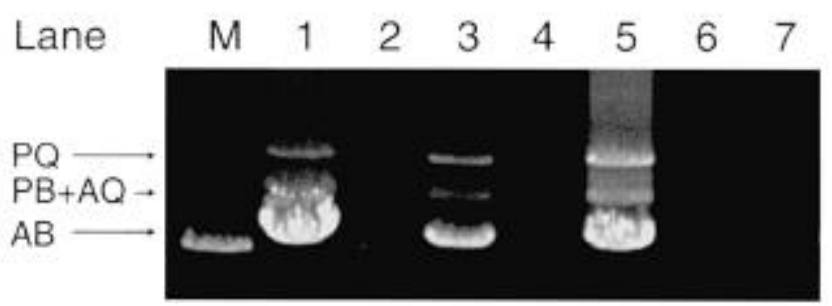

B

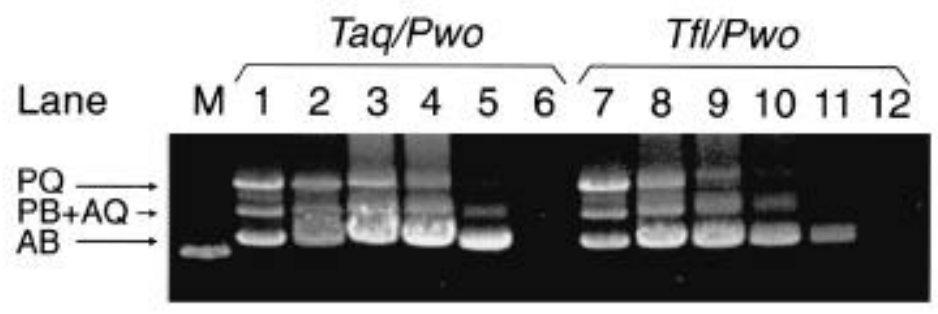

Figure 4. (A) The effect of DMSO and deaza-dGTP. $0.2 \mu \mathrm{M}$ each of primers $\mathrm{P}, \mathrm{Q}, \mathrm{A}$ and $\mathrm{B}$ were used to amplify the carrier DNA template. Lanes 1 and 2: standard three-temperature PCR $\left(94^{\circ}, 65^{\circ}\right.$ and $\left.68^{\circ} \mathrm{C}\right)$; lanes 3 and 4: three-temperature PCR, but the annealing temperature is lowered from $65^{\circ}$ to $60^{\circ} \mathrm{C}$; lanes 5-7: two-temperature PCR $\left(94^{\circ}\right.$ and $\left.65^{\circ} \mathrm{C}\right)$. The samples in the first of each pair of lanes were amplified with optimal concentration of DMSO (7.5\%), deaza-dGTP (37.5\%) and Taq and Pwo polymerase (2.5 U per $25 \mu \mathrm{L}$ reaction). In lanes 2 and 4 , the maximum concentration of DMSO recommended by Boehringer Mannheim (2\%), no deaza-dGTP and the maximum enzyme concentration recommended by Boehringer Mannheim (1.2 U). In lanes 6 and 7, amplification was performed as in lane 5, except with $2 \%$ DMSO (lane 6) or the absence of deaza-dGTP (lane 7). (B) The effect of enzyme concentration. Lanes 1-6, Taq and $P$ wo polymerase at $10,5,2.5,1.25,0.62$ and $0.31 \mathrm{U}$ per $25 \mu \mathrm{L}$ reaction, respectively; Lane 7-12, with $T f l$ and $P w o$ polymerase (30:1, U:U). Two-temperature PCR was performed with $7.5 \%$ DMSO and 37.5\% deaza-dGTP. M = Size standard, only the 9.4-kb segment is shown (200 $\mathrm{ng}$ of $\lambda \mathrm{DNA} /$ HindIII)

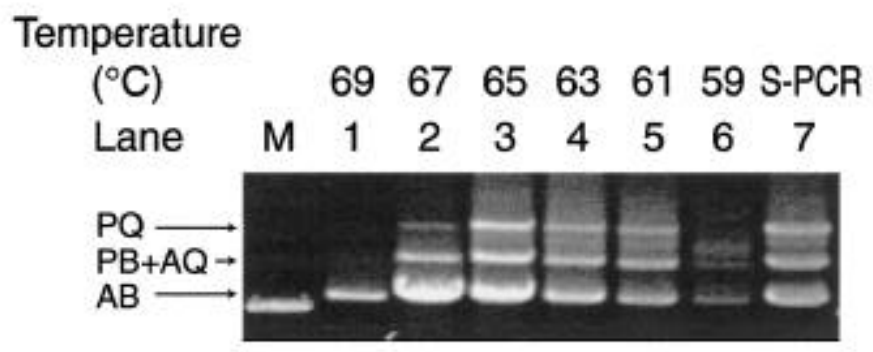

Figure 5. The effect of annealing/elongation temperature and S-PCR. Primers P, Q, A and B were used to amplify the carrier DNA template with each primer at $0.2 \mu \mathrm{M}$ concentration. Two-temperature PCR was used with annealing/elongation temperatures varying from $69^{\circ}-59^{\circ} \mathrm{C}$. The PCR was performed with a RoboCycler ${ }^{\circledR}$ Gradient Temperature (Stratagene, La Jolla, CA, USA) with slightly modified periods of denaturation and annealing/elongation designed to be equivalent to amplification of the GeneAmp 9600 Thermal Cycler based on the manufacturer's protocol. In lane 7, S-PCR was performed for comparison. 
To compare standard three-temperature PCR with S-PCR, combinations of two, three and four primers were tested on the carrier templates. For standard PCR, virtually none of segments PQ, $\mathrm{PB}$ and $\mathrm{AQ}$ were amplified in carriers (estimated molar ratios of more than 20:1), when the molar ratios of the primers were equal. Multiple optimization experiments were undertaken, resulting in unequal primer concentrations of $0.4 \mu \mathrm{M}$ for primers $\mathrm{P}$ and $\mathrm{Q}$, and $0.12 \mu \mathrm{M}$ for primers $\mathrm{A}$ and $\mathrm{B}$. These results with optimized primer concentrations were compared with $\mathrm{S}$ PCR utilizing (unoptimized) equal molar ratios of $0.2 \mu \mathrm{M}$ (Figure 6A). The relative yields with three primers in Figure 6A, lanes 4-8 were the most uneven with fourfold differences among the products, in comparison with twofold differences in Figure 6A, lanes 14-18. Similar tendencies were observed when wild-type and inversion genomic DNAs were used (data not shown). The results with two-tempera- ture PCR were intermediate relative to three-temperature PCR and S-PCR (data not shown).

Figure 6B shows the effects on the relative yields when the concentrations of only primers P and Q (lanes 1-6), of only primers A and B (lanes 7-12) or of all the four primers (lanes 13-18) were varied with carrier DNA as template. Small changes in the primer concentration caused dramatic effects on the relative yields of segments $\mathrm{PQ}, \mathrm{AB}$ and $\mathrm{PB}+\mathrm{AQ}$ with three-temperature PCR (Figure 6B, Panel a), but not with S-PCR (Figure 6B, Panel b). Again, two-temperature cycling produced results intermediate to three-temperature PCR and S-PCR (data not shown).

\section{DISCUSSION}

An analysis of the parameters affecting a multiplex PCR assay for the Hemophilia A inversion hotspot is presented. Efficient amplification of this

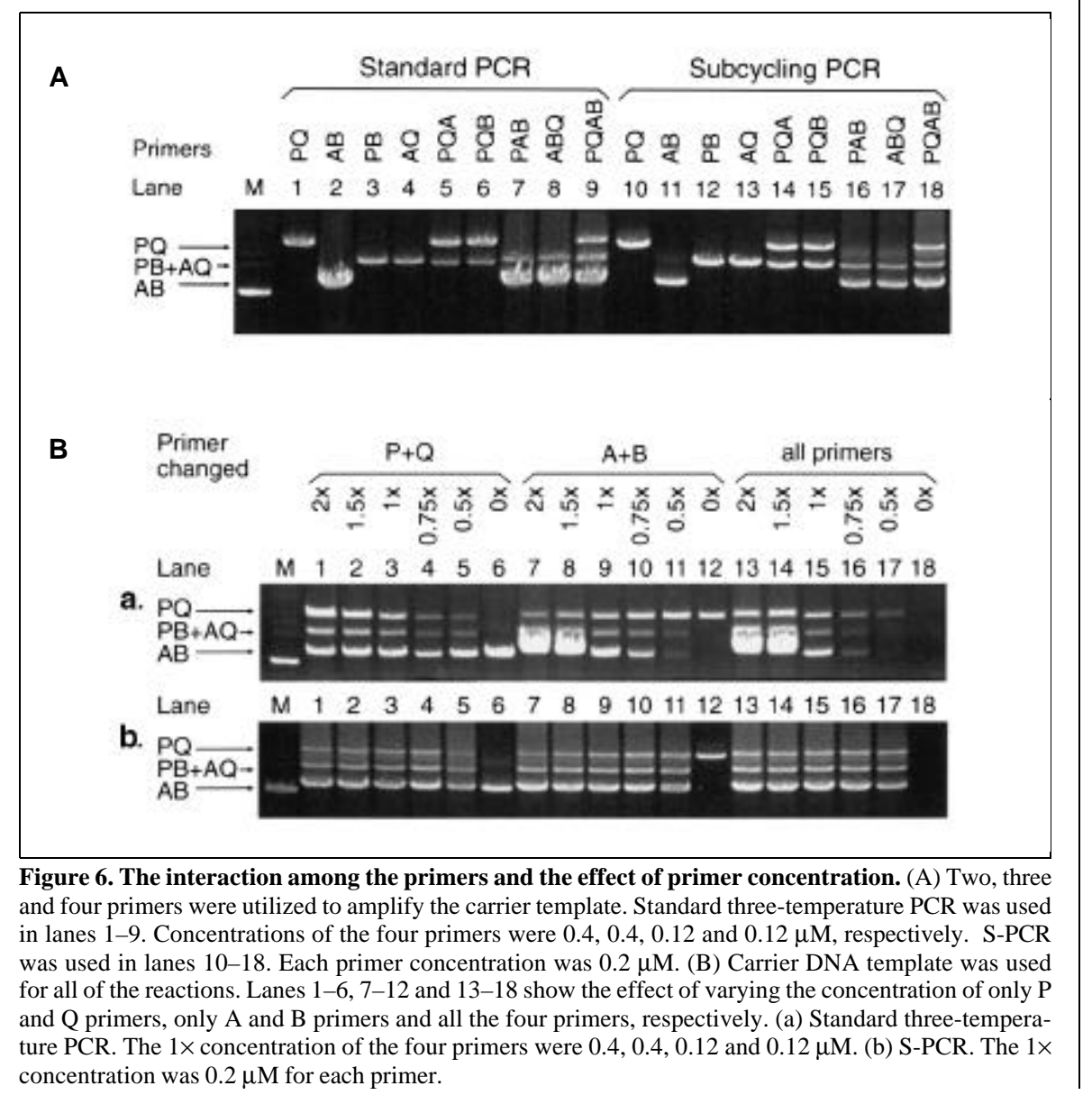


challenging region required very high concentrations of DMSO, the addition of deaza-dGTP and very high concentrations of DNA polymerases. An attempt to find robust conditions for obtaining relatively even amplification of the four segments of overlapping sequence led to the development of $\mathrm{S}$ PCR, which is easier to optimize and is much less affected by the number of primers and their concentrations. In the present system, S-PCR efficiently and evenly amplified the multiplex and overlapping segments and was much less influenced by the primers utilized (PQA, PQB, PAB and ABQ vs. PQAB in Figure 6A) and primer concentrations (Figure 6B). The principle underlying S-PCR (subcycling the annealing/elongation temperature) potentially can provide more robust amplification under situations in which the GC content varies. Thus, S-PCR might facilitate $(i)$ amplification of other long seg- ments in which the GC content varies within the segment and (ii) multiplex amplification of segments in which the GC content of the different segments varies. S-PCR also can be a convenient starting point for optimizing the amplification of long segments of unknown GC content. Further work is required to test this hypothesis.

A few technical points deserve comment. Besides the PCR assay with four primers, two types of three-primer PCR assays, i.e., with primers $\mathrm{P}, \mathrm{Q}$ and $\mathrm{A}$ and with primers $\mathrm{P}, \mathrm{Q}$ and $\mathrm{B}$ also differentiated the wild-type, inversion and carrier states in a single reaction (e.g., Figure 6A). In addition, the amount of template DNA was a factor affecting the relative yields of the products (4). The $\mathrm{PQ}, \mathrm{AB}$ and $\mathrm{PB}+\mathrm{AQ}$ segments were amplified from the carrier DNA template from as little as $12.5 \mathrm{ng}$ per 25 $\mu \mathrm{L}$ of reactions. Finally, a blinded analysis of 40 DNA samples was performed (8). The PCR results were in complete concordance with Southern blot analysis for detection of wild-type, homozygotes and heterozygotes of the factor VIII gene inversion.

\section{ACKNOWLEDGMENTS}

We thank Bill Scaringe for developing the shuffling software, which was utilized to demonstrate random variation in GC content (Figure 1). We thank Dianne Kappas for excellent secretarial assistance. This work was partially supported by National Institutes of Health Grant No. RO1-HL39762.

\section{REFERENCES} J. Horst, P. deMoerloose, S.S. Sommer, R.P. Ketterling, H.H. Kazazian, Jr. et al. 1995. Factor VIII gene inversions in severe hemophilia A: results of an international consortium study. Blood 86:2206-2212.

2.Barnes, W.M. 1994. PCR amplification of up to 35-kb DNA with high fidelity and high yield from lambda bacteriophage templates. Proc. Natl. Acad. Sci. USA 91:2216-2220.

3.Baskaran, N., R.P. Kandpal, A.K. Bhargava, M.W. Glynn, A. Bale and S.M. Weissman. 1996. Uniform amplification of a mixture of deoxyribonucleic acids with varying GC content. Genome Res. 6:633-638.

4.Chamberlain, J.S., R.A. Gibbs, J.E. Ranier, P.N. Nguyen and C.T. Caskey. 1998. Deletion screening of the Duchenne muscular dys- trophy locus via multiplex DNA amplification. Nucleic Acid Res. 16:11141-11156.

5.Cheng, S., C. Fockler, W.M. Barnes and R. Higuchi. 1994. Effective amplification of long targets from cloned inserts and human genomic DNA. Proc. Natl. Acad. Sci. USA 91:5695-5699.

6.Henegariu, O., N.A. Heerema, S.R. Dlouhy, G.H. Vance and P.H. Vogt. 1997. Multiplex PCR: critical parameters and step-by-step protocol. BioTechniques 23:504-511.

7.Lakich, D., H.H. Kazazian, Jr., S.E. Antonarakis and J. Gitschier. 1993. Inversions disrupting the factor VIII gene are a common cause of severe haemophilia A. Nature Genet. 5:236-241.

8.Liu, Q., G. Nozari and S.S. Sommer. 1998. Single-tube polymerase chain reaction for rapid diagnosis of the inversion hotspot of mutation in hemophilia A. Blood 92:1458-1459.

9.Liu, Q., E.C. Thorland, J.A. Heit and S.S. Sommer. 1997. Overlapping PCR for bidirectional PCR amplification of specific alleles: a rapid one-tube method for simultaneously differentiating homozygotes and heterozygotes. Genome Res. 7:389-398.

10.Liu, Q., E.C. Thorland and S.S. Sommer. 1997. Inhibition of PCR amplification by a point mutation downstream of a primer. BioTechniques 22:292-300.

11.Naylor, J., A. Brinke, S. Hassock, P.M. Green and F. Giannelli. 1993. Characteristic mRNA abnormality found in half the patients with severe haemophilia $\mathrm{A}$ is due to large DNA inversions. Hum. Mol. Genet. 2:17731778

12.Naylor, J.A., D. Buck, P. Green, H. Williamson, D. Bentley and F. Giannelli. 1995. Investigation of the factor VIII intron 22 repeated region (int $22 h$ ) and the associated inversion junctions. Hum. Mol. Genet. 4:1217-1224.

13.Ochman, H., A.S. Gerber and D.L. Hartl. 1988. Genetic applications of an inverse polymerase chain reaction. Genetics 120:621-623.

14.Shuber, A.P., V.J. Grondin and K.W. Klinger. 1995. A simplified procedure for developing multiplex PCRs. Genome Res. 5:488-493.

15.Su, X., Y. Wu, C.D. Sifri and T.E. Wellems. 1996. Reduced extension temperatures required for PCR amplification of extremely A+T-rich DNA. Nucleic Acids Res. 24:1574-1575.

16.Wetmur, J.G. 1991. DNA probes: applications of the principles of nucleic acid hybridization. Crit. Rev. Biochem. Mol. Biol. 26:227-259.

Received 20 May 1998; accepted 10 August 1998.

\author{
Address correspondence to: \\ Dr. Steve S. Sommer \\ Director, Departments of Molecular Genetics \\ and Molecular Diagnosis \\ City of Hope National Medical Center \\ 1500 East Duarte Road \\ Duarte, CA 91010-3000, USA \\ Internet:ssommer@coh.org
}

